\title{
Genetics of early cancer detection behaviours in Australian female twins
}

\author{
Susan A Treloar, Christine A McDonald and Nicholas G Martin \\ Cooperative Research Centre for Discovery of Genes for Common Human Diseases, Queensland Institute of Medical \\ Research, Brisbane, Australia
}

\begin{abstract}
Early detection of cervical and breast cancers is an important component of women's health strategy. Screening programmes, health professional interventions and preventive behaviours such as breast self-examination provide the means to this end. Our twin study sought to identify the relative influence of environmental and genetic factors on liability to early cancer detection behaviours, including use of cervical smear tests, mammograms, and breast examination. Additive genetic and random environmental effects models gave the best, most parsimonious fit to the data for each early cancer detection behaviour. The heritability of liability to Pap smear use was $66 \%$, mammogram use $50 \%$, breast examination by a doctor or nurse $38 \%$ and breast self-examination $37 \%$. Genetic influences were behaviour-specific; there was no evidence for a common genetic influence on the four behaviours. Potential covariates investigated included age, amount of contact between co-twins, educational level and personality traits such as harm avoidance, novelty seeking, reward dependence, neuroticism, anxiety, depression, self-esteem, perceived control, interpersonal dependency and ways of coping. None were significant. The study was carried out before the implementation of national screening programmes with media campaigns to increase participation rates. Hence follow-up investigation, including data on regularity of behaviours, would be informative
\end{abstract}

Keywords: health behaviour, cancer screening, genetic influences, twins

\section{Introduction}

Breast cancer is the most common cause of cancer death for Australian women, with a lifetime risk of 1 in $15 .{ }^{1}$ Screening allows for early detection of malignancy with the aim of reducing mortality rates, as most identifiable risk factors for breast cancer are not preventable. ${ }^{2}$ Evidence suggests that mammography is contributing to the reduction in mortality rates from breast cancer. ${ }^{3}$ Early detection of breast cancers allows for considerable treatment cost saving compared with later detection. ${ }^{4}$ Cancer of the cervix is a less common but still significant health problem for Australian women. Early detection and treatment of pre-malignant changes to the cervix can prevent cancer of the cervix. This prevention strategy is based on cervical (Papanicolau or Pap) smear examinations which can detect pre-malignant cell changes. Pap smear testing has been available on an opportunistic basis in Australia since the 1960s, following in the wake of its introduction in countries such as Britain.

We describe a study instigated in 1988, when there were no commonly accepted guidelines on cervical

Correspondence: Susan A Treloar PhD, Queensland Institute of Medical Research, Brisbane QLD 4029, Australia. Tel: +61 73362 0229; Fax: + 6173362 0101. E-mail: sueT@qimr.edu.au

Received 16 November 1998; accepted 16 November 1998 screening frequency in Australia. The Australian National Health and Medical Research Council had recommended three-yearly screening from the start of sexual activity for life (NHMRC 1984), whilst other bodies such as the American College of Obstetrics and Gynecology and the International Academy of Cytology recommended annual screening from age 18 or start of sexual activity for life. ${ }^{5}$ The first Australian guidelines were agreed on in July 1988. ${ }^{6}$ The National Program for the Early Detection of Breast Cancer and the National Policy on Screening for the Prevention of Cervical Cancer were initiated in $1990 .{ }^{7}$ In 1991 Australia introduced the Organised Approach to Preventing Cancer of the Cervix to implement the national policy. ${ }^{8}$ Because of Australia's division of responsibilities between Federal and State Governments, determined by the Constitution, substantial variation exists between States in their level of implementation of national policies. Variability prevailed also prior to the national policy introduction. Nurse practitioners had been performing Pap smears and breast examinations since 1976 in the State of New South Wales, ${ }^{8}$ whereas in the State of Queensland these services were only available from medical practitioners. ${ }^{9}$

The $19 \%$ fall in the number of women who died from cervical cancer in Australia between 1973 and 1993 has been attributed largely to Pap smear 
screening. ${ }^{1}$ Decreases in cervical cancer incidence have been linked with intensity of screening. ${ }^{5}$ However, in 1989 just over one third of cervical cancers in Australia were being prevented by screening. ${ }^{6}$ Comprehensive data have not been available on patterns of use of cervical smear tests in Australia. In one New South Wales study $63 \%$ of women had not had a smear test for eight years or more, and $10 \%$ had never had one. ${ }^{10}$ Concern has been consistently expressed that women identified as being at high risk of cervical cancer are not utilising available screening services. Surveys of women who have presented to physicians with invasive cervical cancer have shown that over $60 \%$ of the women had never undergone a cervical smear test, and this proportion was highest in the older women. ${ }^{11}$

In $1989-90,71 \%$ of women aged $18-64$ years had had a Pap smear in the previous three years, with the highest rate $(86 \%)$ among women aged $25-34$ years. ${ }^{1}$ Women over 40 with the highest risk of cervical cancer had a lower screening rate than younger women at lower risk. ${ }^{1}$ Although cervical screening has contributed to reduction in incidence and mortality due to cervical cancer in many countries, ${ }^{12}$ there is some question about its role in relation to certain groups. Reports have suggested an increasing incidence of early stage cervical intra-epithelial neoplasia (CIN) in younger women, ${ }^{13}$ possibly due to the prevalence of human papilloma virus. Mortality rates have been rising amongst young women in Australia. ${ }^{12}$

Public health campaigns promoting use of screening procedures are costly, ${ }^{14}$ underlining the importance of understanding what lies behind use of early cancer detection behaviours (ECDBs). Cancer prevention directed behaviours may include general activities such as dietary modification. Other behaviours are specific in intent and purpose. These may be private activities: for example, women are encouraged to practise monthly breast self-examination to detect breast changes or lumps, over and above regular health practitioner consultation and/or mammography screening at the recommended interval for their risk group. Others involve attendance for consultation at a medical practice or health service and consent to examination or procedure. We focus on specific activities relating to prevention of cervical and breast cancers.

Why do some women attend to screening or engage in regular self-examination, whilst others do not? A further important question is whether there are socioeconomic covariates or identifiable predisposing or inhibiting psychological factors relating to early cancer detection behaviours. Education has been shown to be an important predictor of a number of health outcomes and interventions, and lower educational attainment may be hypothesised as a risk factor for low levels of ECDB, for example because of lack of awareness of the role of ECDB in preventing cancer.

There is a large literature reporting investigations of the role of personality type or psychological factors such as self-esteem, 'locus of control' (internal or external) or attributional styles and coping in a wide range of specific diseases and health-related and treatment-seeking behaviours. The Health Belief Model has been proposed since the 1950 s as a predictor of preventive health behaviour ${ }^{15}$ such as participation in a screening programme. ${ }^{9}$ We therefore considered it important to investigate psychological factors as possible covariates of ECDB items.

Familial patterns have been shown to have an impact on health care use and treatment-seeking behaviour, as well as on disease susceptibility, with genetic factors contributing substantially to variability. ${ }^{16}$ We sought to identify the contributions to variation in both individual preventive behaviour and in screening compliance behaviour using a classic twin study design comparing differences of monozygotic (MZ) and dizygotic (DZ) twins reared together. $^{17,18}$ We describe an exploratory study which sought to examine the genetic and environmental influences on early cancer detection behaviours for both cervical and breast cancers, and their association with potential socio-demographic and psychological covariates.

\section{Materials and methods}

\section{Sample}

Participants were members of a cohort of 1979 female twin pairs, ascertained originally in 1980-82 from the Australian National Health and Medical Research Council Twin Register, ${ }^{19-21}$ and followed up in 1988-90 when the minimum age of respondents was 25 years. ${ }^{22-24}$ The 1988 questionnaire included items on age, sex, zygosity, birth order, level of contact, education, reproductive history, psychological traits and a number of physical and psychiatric symptoms. The questionnaire replicated most of the earlier questions and added new health items for women including early cancer detection behaviours. A two-year follow-up was carried out following the 1989 survey in order to measure medium-term stability of reports over time. Identical questionnaires were mailed in 1990 to the first 500 female individual twins who responded in 1988.

Responses to the 1988 questionnaire were obtained from both members of 1504 female twin pairs (952 MZ pairs and $552 \mathrm{DZ}$ pairs). Additional 
twins participated in an abbreviated telephone interview form of the questionnaire, giving a total pairwise response rate of $82 \% \quad(n=1620$ of the original 1979 pairs). This pairwise response rate increased to $90 \%$ if pairs where either twin had a known physical barrier to participation such as being overseas or was deceased ( $n=171$ pairs) were excluded from the total.

Two items concerning similarity in appearance and being mistaken by others were included to determine zygosity. ${ }^{19}$ Pairs giving inconsistent responses were recontacted for clarification. Such questionnaires have been shown to give at least $95 \%$ agreement with diagnosis based on extensive bloodtyping. ${ }^{25-27}$ More recently, members of a subsample of 198 same-sex pairs from this group, who reported themselves to be MZ, were typed for 11 independent highly polymorphic markers in the course of an asthma study; no errors in our previous zygosity diagnosis were detected. $^{28}$ Of 131 like-sex pairs (male and female) who reported themselves to be DZ and who had DNA available, five (38\%) were concordant at the 11 loci, with a probability of monozygosity of over 0.9999 . This gave a sensitivity for self-report monozygosity of 0.98 (exact $95 \%$ CI 0.94-0.99) and a specificity of $1.00(0.97-1.00)$ in this sample. ${ }^{28}$

\section{Items}

Early cancer detection behaviours (ECDB) Female twins were asked to answer the following questions:

1. 'Have you ever had a (Pap) smear test for cancer of the cervix? Yes No' (PAP)

2. 'Do you check your own breasts for lumps or changes? No Yes, occasionally Yes, monthly' (Breast self-examination or BSE)

3. 'Have you ever had a breast examination by a doctor or nurse? Yes No' (Breast examination or $\mathrm{BE})$

4. 'Have you ever had a mammogram (breast X-ray)? Yes No' (MAM)

When the present study was implemented mammography was used primarily for diagnostic rather than screening purposes. Variables were recoded for consistent direction.

Hypothesised covariates Variables tested for association with each ECDB item were age, level of contact between co-twins (to assess relationship with ECDB similarity, one aspect of equal environments assumption), and educational level. Age at response was included because of the increased risk of breast and cervical cancers associated with advancing age, and because of concern that ECDBs were not sufficiently practised by women in the age groups most at risk. Age was calculated from the twin's date of birth and date of return of the survey.

Fundamental to the twin method is the assumption that the environments of MZ co-twins are no more similar than those of DZ co-twins - or if they are, that this does not influence intrapair similarity in the variable being analysed. Environmental similarity was measured by level of contact between co-twins. Level of contact was determined from responses to the following question: 'How often have you and your twin SEEN and CONTACTED each other during the last few years? (1) We live together, (2) Almost every day, (3) At least once a week, (4) Once or twice a month, (5) A few times a year, (6) Less often, (7) Not at all.' Twins were asked to check one of these seven responses for seeing and contact with their co-twin for each of the previous 9 years (since the 1980-82 survey). A general contact variable for each year was created by taking the lower number (higher level of contact) of each of the SEEN and CONTACTED responses. This information was then condensed into an overall contact variable by averaging the general contact variable over the 9 years.

Highest educational level achieved was assessed on a 7 category scale: (1) Less than 7 years' schooling, (2) 8-10 years' schooling, (3) 11-12 years' schooling, (4) Apprenticeship, diploma, etc. (5) Technical or Teachers' College, (6) University first degree, (7) University post-graduate training. Categories were collapsed into four better to reflect real distinctions between levels of attainment and to increase small cell sizes at each end of the scale: (1) 1 and 2; (2) 3 ; (3) 4 and 5; (4) 6 and 7.

Major items included in the questionnaire were a short form 54-item version of the Tridimensional Personality Questionnaire (TPQ) ${ }^{29}$ and the shortform 48-item revised Eysenck Personality Questionnaire (EPQ-R(S)). ${ }^{30}$ The TPQ was designed to assess three higher order personality dimensions defined by Cloninger's unified biosocial theory of personality: ${ }^{31}$ Harm Avoidance (plus four subscales of anticipatory worry and pessimism, tension about uncertainty or physical danger, shyness with strangers, fatiguability and asthenia), Novelty Seeking (with six dimensions of exploratory versus rigid, disorderly versus regimented, excitable/fickle versus stoic/loyal, impulsive versus reflective, dramatic/ talkative versus laconic/listener, extravagant versus frugal plus three subscales of exploratory excitability versus stoic rigidity, impulsiveness versus reflection, extravagance versus reserve), and Reward Dependence (with two subscales of social sensitivity versus detachment, and persistence). The short-form EPQ- 
$\mathrm{R}(\mathrm{S})$ assesses the personality dimensions of Extraversion (E); Neuroticism (N); Social Conformity or Lie (L), and Toughmindedness, or Psychoticism (P). ${ }^{32}$ Anxiety and depression were assessed by the seven sA and seven sD items from the validated DelusionsSymptoms-States-Inventory (DSSI) ${ }^{33,34}$ and 19 items from the Hopkins Symptom Check List (SCL). ${ }^{35,36}$ Ten self-esteem items ${ }^{37}$ were included. Eight items based on Pearlin and Schooler's mastery scale were used to formulate 'perceived control', conceptualised as a characteristic concerning the extent to which one's life chances were under one's own control or that of fate. ${ }^{38}$ Ten interpersonal dependency items based on the Emotional Reliance on Another Person dimension of the Interpersonal Dependency Inventory ${ }^{39}$ were chosen to reflect need to rely on valued others. ${ }^{40}$ Thirteen 'ways of coping' items $^{41,42}$ comprising three factors of reliance on social support, problem-focused coping and denial factors ${ }^{43}$ were also included.

We proposed that poor compliance with or lower rates of ECDBs would be associated with personality and psychological phenotypes as follows: low Neuroticism, high Psychoticism, high Lie, low Reward Dependence, low Novelty-Seeking, low Harm Avoidance, higher depression and lower anxiety scores, lower self-esteem, higher interpersonal dependency, lower perceived control, higher denial, lower problem-focused coping and higher 'turning to others' coping scores.

\section{Data summary and model-fitting}

The liability to each ECDB is assumed to have an underlying normal distribution. The appropriate statistic that estimates this correlation in liability between twins is the polychoric correlation, of which the special case for a dichotomous variables is the tetrachoric correlation. To overcome scaling problems while retaining the characteristics of the original distributions, categories were created for the larger psychological scales by subtracting the number which would make ' 1 ' the lowest category, then dividing the continuous score to reduce it to less than 15, the maximum number of categories allowable for calculation of polychoric correlations in PRELIS.

Matrices of correlations, and corresponding asymptotic covariance matrices, were computed separately for MZ and DZ twin pairs using PRELIS $2.12{ }^{44}$ Genetic models were fitted by the method of asymptotic (weighted) least squares (WLS) using LISREL 8. ${ }^{45}$ Genetic models estimating the contributions of additive genetic $(a)$, shared or common environment $(c)$ or nonadditive genetic influences (d) such as dominance or epistasis, ${ }^{46}$ and non-shared or specific $(e)$ environmental effects. Genetic non- additivity and shared environment are completely confounded in data on twin pairs reared together ${ }^{17,47}$ and only one of them may be estimated.

We proceeded by systematically testing the significance of dropping parameters in turn. In addition to the likelihood ratio $\chi^{2}$ test (LR), the Akaike Information Criterion (AIC, measured as $\chi^{2}-2 \mathrm{df}$ ) was used as an additional indicator of fit. The model using the smallest number of different parameters to produce accurately the observed correlations is accepted as the best model and thus the 'simplest' explanation of the data (principle of parsimony). Univariate model-fitting proceeded through a systematic process of fitting of a full model containing $a, c$, and $e$ (ACE model), then an AE model dropping $c$, a CE model dropping $a$, and then a full ADE followed by a nested E only model with both $a$ and $d$ dropped to assess effect on fit (see Results, Table 5). For multivariate model-fitting we used a saturated Cholesky (genetic decomposition) model to explain sources of variation and covariation. ${ }^{48}$ Twin pair data analysis methods are described more fully elsewhere. ${ }^{48-51}$ Following multivariate model-fitting, parameter estimates were rotated independently using varimax rotation in SAS. ${ }^{52}$

\section{Results}

\section{Test-retest reliability of ECDB items}

Changes in twins' responses between 1988 and 1990, and polychoric correlations between original responses to the four ECDB questions and follow-up responses are shown in Table 1 . Repeatability was highest for PAP and MAM. It is feasible that responses that were originally 'no' legitimately changed to 'yes' over the two years between the original mailing and the follow-up survey. Inconsistent answers, those that changed from 'yes' to 'no', should be equally as likely as those that are not legitimate changes from 'no' to 'yes'. By setting the number of changes of 'no' to 'yes' to be equal to the number of changes of 'yes' to 'no', with the remaining number of changes of 'no' to 'yes' being deemed the legitimate changes, correlations were recomputed and coefficients increased in magnitude, particularly in the case of mammograms (see Table 1).

\section{Covariates}

Age Of the 3903 individual females who responded to the survey, 3771 (96.6\%) answered all four ECDB questions. The sample was divided into age bands: 24-29, 30-39, 40-49, 50-59, 60-69 and 70+ years. Frequencies of response by age group are shown in Table 2. 
Reported participation in early cancer detection behaviours differed according to age at response. Endorsement of having had a Pap smear test was lower in the youngest and oldest age groups, and was especially low in the group aged 70 and above. Rates of endorsement were very high among women in their middle years. There appear to be similar participation levels in breast self-examination across age groups although the majority of women were not performing BSE monthly and a higher number were never using it as an ECDB. BSE was much less common than BE, although for women aged 60 and over reported BE was lower than BSE. Low participation in MAM was expected as screening programmes for breast cancer were not widespread at the time of the study. Younger women had the lowest level of participation, but the relatively low rate for women aged 60 and above was noteworthy given their increased risk.
The sample was divided into two groups at the median age - the younger group aged 38 years or less and the older group aged 39 years or more - to assess differences in twin pair correlations between groups. Correlations were consistent across age groups (see Table 3). Although the pooled correlations were slightly inflated in comparison with the component correlations for each age group, we considered that the effect would not account for more than a trivial proportion of the variance, and age was not included as a covariate in model-fitting.

Level of contact Categories were collapsed into two categories of contact - high versus low (see Table 4). Twin pair correlations did not differ for low and high contact pairs, suggesting that although MZ co-twins are in higher overall contact, their greater similarity for each ECDC was unlikely to be caused by greater MZ co-twin contact.

Table 1 Changes in response 1988 to 1990 and test-retest repeatability coefficients

\begin{tabular}{|c|c|c|c|c|c|c|c|c|}
\hline \multirow[b]{3}{*}{ Response in 1988} & \multicolumn{8}{|c|}{ Response in 1990} \\
\hline & \multicolumn{2}{|c|}{$P A P^{a}$} & \multicolumn{2}{|c|}{$B S E$} & \multicolumn{2}{|c|}{$B E$} & \multicolumn{2}{|c|}{$M A M$} \\
\hline & Yes & No & Yes & No & Yes & No & Yes & No \\
\hline Yes & 402 & 5 & 367 & 31 & 356 & 16 & 89 & 11 \\
\hline No & 10 & 33 & 16 & 33 & 31 & 45 & 53 & 294 \\
\hline & $r$ & $S E$ & $r$ & $S E$ & $r$ & $S E$ & $r$ & $S E$ \\
\hline Polychoric $r^{\mathrm{b}}$ & 0.97 & 0.02 & 0.81 & 0.06 & 0.85 & 0.04 & 0.90 & 0.03 \\
\hline Polychoric $r^{\mathrm{c}}$ & 0.98 & 0.02 & 0.88 & 0.04 & 0.91 & 0.03 & 0.98 & 0.01 \\
\hline
\end{tabular}

${ }^{\text {aPAP }}=$ ever had a Pap smear; BSE = performing breast self-examination; BE = ever had a breast examination; MAM = ever had a mammogram.

bfrom data as tabled.

callowing for legitimate changes from No in 1988 to Yes in 1990 by equating -(88)+(90) to +(88)-(90).

Table 2 Frequencies of responses to the early cancer detection behaviour items in 1989 for female twins by age band

\begin{tabular}{|c|c|c|c|c|c|c|c|c|c|c|}
\hline \multirow[b]{3}{*}{ Age band } & \multirow[b]{3}{*}{$n$} & \multicolumn{2}{|c|}{$P A P^{a}$} & \multicolumn{3}{|c|}{$B S E$} & \multicolumn{2}{|c|}{$B E$} & \multicolumn{2}{|c|}{$M A M$} \\
\hline & & Yes & No & Monthly & Occasionally & No & Yes & No & Yes & No \\
\hline & & $\%$ & $\%$ & $\%$ & $\%$ & $\%$ & $\%$ & $\%$ & $\%$ & $\%$ \\
\hline $24-29$ & 701 & 86 & 14 & 13 & 69 & 18 & 67 & 33 & 5 & 95 \\
\hline $30-39$ & 1304 & 96 & 4 & 19 & 68 & 13 & 78 & 22 & 13 & 87 \\
\hline $40-49$ & 858 & 96 & 4 & 24 & 65 & 11 & 84 & 16 & 26 & 74 \\
\hline $50-59$ & 442 & 93 & 7 & 23 & 68 & 9 & 87 & 13 & 33 & 67 \\
\hline $60-69$ & 332 & 82 & 18 & 22 & 62 & 16 & 77 & 23 & 21 & 79 \\
\hline $70+$ & 134 & 64 & 36 & 12 & 73 & 15 & 58 & 42 & 19 & 81 \\
\hline Total & 3771 & 92 & 8 & 19 & 67 & 14 & 78 & 22 & 18 & 82 \\
\hline
\end{tabular}

Table 3 Twin pair correlations (standard errors) by zygosity and age group

\begin{tabular}{|c|c|c|c|c|c|c|}
\hline Zygosity & Age group & $n$ pairs & $P A P$ & $B S E$ & $B E$ & $M A M$ \\
\hline $\mathrm{MZ}$ & $\begin{array}{l}\text { Younger }^{\mathrm{a}} \\
\text { Older }^{\mathrm{b}} \\
\text { Total }\end{array}$ & $\begin{array}{l}441 \\
444 \\
885\end{array}$ & $\begin{array}{l}0.67(0.09) \\
0.68(0.08) \\
0.68(0.06)\end{array}$ & $\begin{array}{l}0.37(0.07) \\
0.37(0.06) \\
0.38(0.04)\end{array}$ & $\begin{array}{l}0.32(0.08) \\
0.45(0.09) \\
0.40(0.06)\end{array}$ & $\begin{array}{l}0.47(0.10) \\
0.46(0.07) \\
0.51(0.05)\end{array}$ \\
\hline DZ & $\begin{array}{l}\text { Younger } \\
\text { Older } \\
\text { Total }\end{array}$ & $\begin{array}{l}262 \\
261 \\
523\end{array}$ & $\begin{array}{l}0.24(0.19) \\
0.14(0.18) \\
0.19(0.13)\end{array}$ & $\begin{array}{l}0.21(0.09) \\
0.14(0.09) \\
0.18(0.06)\end{array}$ & $\begin{array}{l}0.14(0.11) \\
0.13(0.13) \\
0.15(0.08)\end{array}$ & $\begin{array}{l}0.19(0.17) \\
0.17(0.11) \\
0.24(0.09)\end{array}$ \\
\hline
\end{tabular}

aged 38 years or less; baged 39 years or more. 
Table 4 Twin pair correlations by zygosity and level of contact of co-twins

\begin{tabular}{|c|c|c|c|c|c|c|}
\hline Zygosity & $\begin{array}{l}\text { Contact } \\
\text { Level }^{\mathrm{a}}\end{array}$ & $\begin{array}{c}n \\
\text { pairs }\end{array}$ & $\begin{array}{c}P A P \\
r(S E)\end{array}$ & $\begin{array}{c}B S E \\
r(S E)\end{array}$ & $\begin{array}{c}B E \\
r(S E)\end{array}$ & $\begin{array}{l}M A M \\
r(S E)\end{array}$ \\
\hline MZ & $\begin{array}{l}\text { Low }^{\mathrm{a}} \\
\text { High }^{\mathrm{b}} \\
\text { Total }\end{array}$ & $\begin{array}{l}256 \\
627 \\
883\end{array}$ & $\begin{array}{l}0.73(0.10) \\
0.65(0.07) \\
0.68(0.06)\end{array}$ & $\begin{array}{l}0.32(0.09) \\
0.39(0.05) \\
0.38(0.04)\end{array}$ & $\begin{array}{l}0.26(0.12) \\
0.44(0.06) \\
0.40(0.06)\end{array}$ & $\begin{array}{l}0.58(0.09) \\
0.48(0.07) \\
0.51(0.05)\end{array}$ \\
\hline DZ & $\begin{array}{l}\text { Low } \\
\text { High } \\
\text { Total }\end{array}$ & $\begin{array}{l}259 \\
264 \\
523\end{array}$ & $\begin{array}{l}0.22(0.21) \\
0.16(0.17) \\
0.19(0.13)\end{array}$ & $\begin{array}{l}0.22(0.08) \\
0.13(0.10) \\
0.18(0.06)\end{array}$ & $\begin{array}{l}0.15(0.11) \\
0.16(0.12) \\
0.15(0.08)\end{array}$ & $\begin{array}{l}0.23(0.12) \\
0.26(0.13) \\
0.24(0.09)\end{array}$ \\
\hline
\end{tabular}

aThe low contact group included twins who were in contact once or twice a month, a few times a year, less often or not at all; ${ }^{\mathrm{T}}$ The high contact group included twins who either lived together, contacted each other almost every day, or at least once a week.

Educational level Correlation coefficients between the four-level highest educational attainment with the ECDB of interest were PAP $(r=0.02)$, BSE $(r=0.002)$, BE $(r=-0.02)$ and MAM $(r=0.12)$ $(n=3740)$. We did not therefore include education in multivariate model-fitting.

Psychological measures Sample sizes without missing values for phenotypic correlations ranged from $n=3032$ to $n=3730$. Correlation coefficients were at best extremely modest for all scales and subscales. The strongest associations were related to PAP: the largest coefficient was with the TPQ Reward Dependence subscale of social sensitivity $(r=0.18)$, the second largest coefficient $(r=0.16)$ suggesting a small association with the TPQ Novelty Seeking dimension of 'extravagant vs frugal)', the third largest was the inverse correlation with the shyness with strangers subscale of the TPQ Harm Avoidance dimension $(r=-0.15)$. Others were negligible.

The highest correlation between any ECDB and the EPQ-R(S) Neuroticism dimension was with BSE $(r=0.07)$. Extraversion was negatively correlated at very low levels $(<0.09)$ with all ECDBs. The strongest association involving self-esteem, interpersonal dependency, perceived control and ways of coping was $r=-0.10$ between BSE and problemfocused coping. We had proposed that Harm Avoidance (HA) might be related to ECDB, but found very low associations (with PAP $r=0.07$, with BSE $r=0.07$, with BE $r=0.07$ and with MAM $r=0.00$ ). Because the correlations were all of such low magnitude, none was included in subsequent multivariate model-fitting.

\section{Univariate genetic analysis}

In the case of each ECDB, the AE model without shared environment offered a fit not significantly worse than the ACE model (see Table 5). Dropping additive genetic influences from the model (CE) in all cases resulted in a significant worsening of fit. Nonadditive genetic influences, although indicated where the MZ correlation is more than twice the DZ correlation, could be dropped from the model without significantly worsening fit. The E model offers a significantly worse fit for each ECDB, indicating substantial familial aggregation for response to PAP, BSE, BE and MAM.

The heritability of liability to having had a Pap smear was the strongest at $66 \%$, with the breast examination variables showing similar heritabilities (37\% for BSE and $38 \%$ for BE). Liability to having had a mammogram had a higher genetic contribution of $51 \%$ of total variance (see Table 5).

\section{Multivariate genetic analysis}

The four ECDBs were variably phenotypically intercorrelated. The highest coefficients were between BE and MAM $(r=0.57)$ and BE and PAP $(r=0.47)$, where all involved a medical or nurse consultation, even though the latter two related to different cancers. It is feasible that a breast examination and mammography, although carried out by different practitioners, could relate to the same health episode. The association between BE and BSE was lower $(r=0.26)$, as was that between MAM and BSE $(r=0.26)$, although both activities related to breast cancer. Lower still was the association between PAP and BSE $(r=0.16)$, where one ECDB was consultation-related and the other a private activity, in the latter case relating to different cancers. The correlation between PAP and MAM was also modest $(r=0.21)$, although both involved consultations.

The extent of genetic and environmental covariation between the four ECDBs was assessed by fitting an atheoretical Cholesky decomposition model to polychoric correlation and asymptotic covariance matrices. As univariate analyses had suggested the $\mathrm{AE}$ model to be the best fitting and most parsimonious model, we fitted a double (AE) Cholesky model containing only additive genetic and specific environmental parameters. This model offered a good fit with $\chi_{40}^{2}=33.18(P=0.77, \mathrm{AIC}=-46.82)$. Estimates of contributions to variance and covariance are shown in Table 6. Parameter estimates for the four 
Table 5 Twin pair polychoric correlations and proportions of variance from univariate genetic model-fitting for early cancer detection behaviours

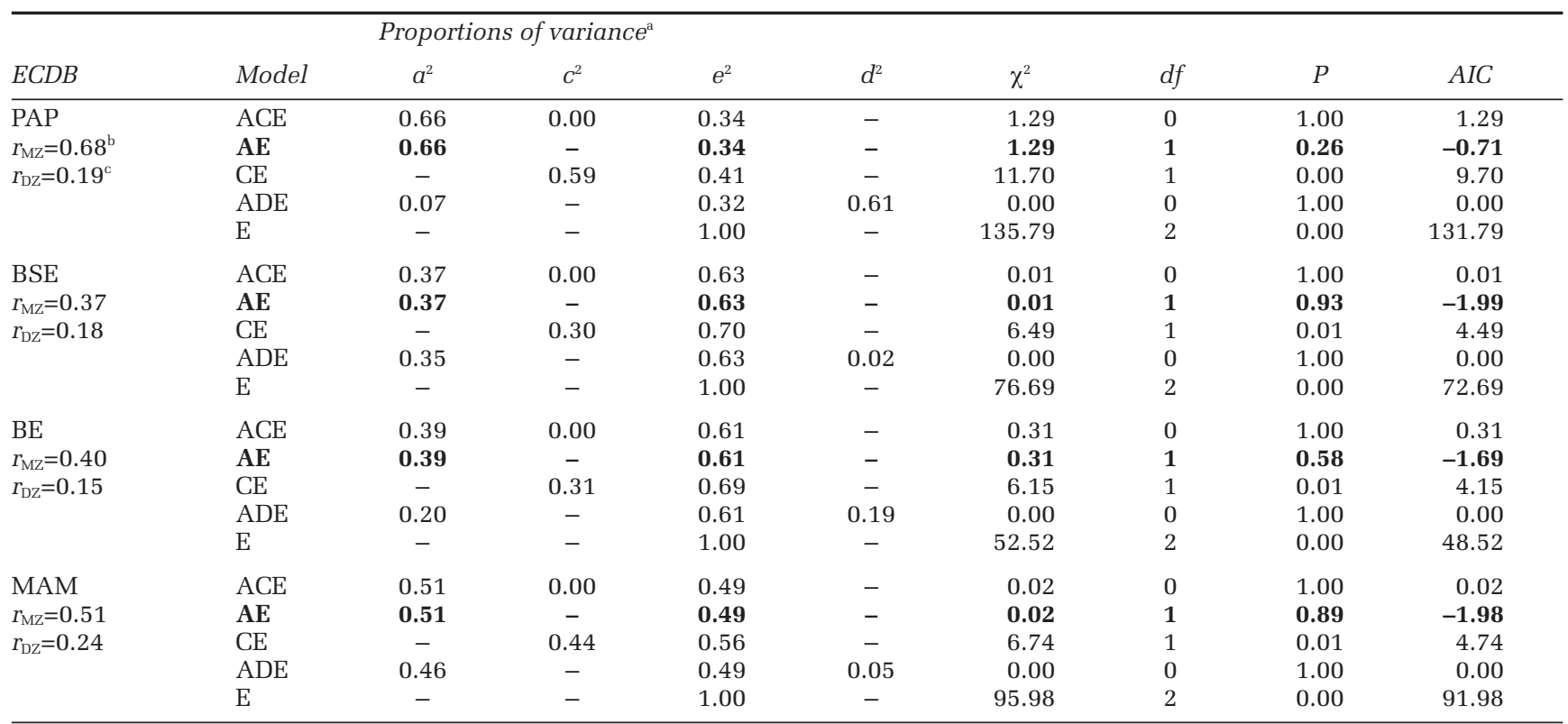

Best-fitting, most parsimonious models are in bold; ${ }^{\mathrm{a}} a^{2}=$ additive genetic influences; $c^{2}=$ common environment; $e^{2}=$ unique environmental influences; $d^{2}=$ non-additive genetic influences; ${ }^{\mathrm{b}} \mathrm{MZ} n=885$ pairs; ${ }^{\mathrm{D} Z} \mathrm{D} n=523$ pairs.

Table 6 Multivariate Cholesky decomposition of variance and covariance for four ECDB items (AE model)

\begin{tabular}{|c|c|c|c|c|c|c|c|c|c|c|}
\hline \multirow[b]{3}{*}{$E C D B$} & \multicolumn{10}{|c|}{ Proportions of variance } \\
\hline & \multicolumn{5}{|c|}{ Genetic factors } & \multicolumn{5}{|c|}{ Unique environmental factors } \\
\hline & $A 1$ & $A 2$ & $A 3$ & $A 4$ & Total & E1 & E2 & E3 & $E 4$ & Total \\
\hline$\overline{\mathrm{PAP}}$ & 0.66 & & & & 0.66 & 0.34 & & & & 0.34 \\
\hline BSE & 0.02 & 0.36 & & & 0.38 & 0.00 & 0.62 & & & 0.62 \\
\hline $\mathrm{BE}$ & 0.18 & 0.03 & 0.18 & & 0.39 & 0.08 & 0.01 & 0.52 & & 0.61 \\
\hline MAM & 0.01 & 0.07 & 0.19 & 0.24 & 0.51 & 0.03 & 0.01 & 0.10 & 0.35 & 0.49 \\
\hline
\end{tabular}

additive genetic and the four individual environmental factors were rotated independently using varimax rotation in SAS (see Table 7).

Genetic covariation between the ECDBs was minimal, with the exception of a loading from $\mathrm{BE}$ on the first genetic factor (a PAP factor), suggesting some common genetic influence. Environmental covariation was low in all cases. Results suggested that no common factor, either environmental or genetic, underlies the four behaviours and that fitting a common pathway model to the data was not warranted.

Table 7 Genetic and environmental parameter estimates following independent varimax rotation of factor estimates, with factors reordered

Parameter estimates

Genetic factors

Unique environmental factors

\begin{tabular}{lccccccccc}
$E C D B$ & $A 1$ & $A 2$ & $A 3$ & $A 4$ & $E 1$ & $E 2$ & $E 3$ & $E 4$ \\
\hline PAP & 0.79 & 0.06 & 0.17 & 0.04 & 0.58 & 0.02 & 0.09 & 0.06 \\
BSE & 0.05 & 0.59 & 0.07 & 0.10 & 0.03 & 0.79 & 0.07 & 0.06 \\
BE & 0.31 & 0.12 & 0.45 & 0.26 & 0.14 & 0.08 & 0.74 & 0.21 \\
MAM & 0.05 & 0.14 & 0.15 & 0.69 & 0.07 & 0.18 & 0.18 & 0.67 \\
\hline
\end{tabular}




\section{Discussion}

The analysis of causes of individual differences in early cancer detection behaviours has produced evidence of specific genetic influences on the liability to each of the four behaviours: Pap smear, breast self-examination, breast examination and mammogram. Despite modest to strong phenotypic intercorrelations between the variables, the only genetic covariation identified was between PAP and BE. It is plausible, given the finding that genetic influences may influence health treatment-seeking behaviour, ${ }^{16}$ that there is a predisposition towards either initiating or complying with available health care directed at prevention by early diagnosis. We had no other measures of use of primary health care services with which to compare these findings. These behaviours appear to be distinct in aetiology from the private behaviour of breast self-examination.

The strongest genetic influences were identified for liability to ever having had a Pap smear. A plausible explanation of this finding is difficult, and was not suggested by any of the covariates tested. If it were the age of first Pap smear, possibly age of onset of sexual activity might be suggested. It is possible that a sexual activity factor might be involved, such as number of partners influencing perceived risk. A Pap smear involves willingness to undergo a vaginal examination by a doctor (or less frequently a nurse) and there can be some discomfort or, occasionally, pain. Factors may include fear of the process, being too busy caring for family members to think about their own health, or being embarrassed, especially if the doctor is male. These factors may not be assessed by the psychological measures included in the questionnaire. It is interesting that in one Australian study almost a quarter of the women screened had their Pap smear taken in the context of their use of either contraception or hormones, or in connection with either pregnancy or a postpartum visit. ${ }^{53}$ Oral contraceptive use has been associated with the decision to have a cervical smear test in other studies. ${ }^{11}$ Genetic influences are plausible on these factors as possible covariates, and may justify further investigation. Mammography in our study would have been primarily used in response to signs or symptoms, so its meaning cannot be readily extended to asymptomatic women's predisposition to engage in mammographic screening. The genetic influences identified may relate in part at least to breast symptoms. Any effect of (knowledge of) family history would be identified as a shared environmental influence.

Despite a noticeably higher frequency of negative response by women in the older age group to the questions on Pap smear and breast examination, age was not relevant as a covariate for genetic analyses. None of the other hypothesized covariates - level of contact, educational level and personality scores for harm avoidance, novelty seeking, reward dependence, neuroticism, anxiety, depression, self esteem, perceived control interpersonal dependency and ways of coping - was found to be significant. Clearly there is a need for further investigation to find measures that do have explanatory relevance.

One might have expected genetic influences to be stronger on a private behaviour like BSE, but the proper technique does need to be taught to women by a health practitioner in the first instance and practitioner reinforcement of the practice may well be important for its continuation. In addition to women's own knowledge and motivation, health service and practitioner factors may constitute important environmental influences affecting each ECDB. Continuity of care from a general practitioner and increased length of attendance at a practice has been linked to better practice of preventive health behaviours such as breast self-examination and having regular Pap smears. ${ }^{54}$ There was no evidence from our data that environmental factors were the same for any two behaviours, however. Environmental influences were less important for having had a Pap smear than the other behaviours, and were more important for BSE - possibly the need for reinforcement. Many factors may reduce the likelihood of a doctor suggesting a Pap smear during a medical consultation, particularly when the consultation was not for a pelvic problem. ${ }^{10}$ Evidence suggests that even following the introduction of the national guidelines, many doctors are still unaware of or were not implementing the guidelines for cervical screening in their practices. ${ }^{55}$ In many areas of Australia medical practitioners are the only health professionals available to perform cervical smears and breast examinations, and many other inhibitory factors exist. ${ }^{9}$

The female twins have been shown to be representative of the Australian population on a variety of indicators including age, general level of education and marital status. ${ }^{56}$ Twins have volunteered to participate in medical research in general and are unselected for any particular characteristics. With regard to the test-retest survey for repeatability, however, the first 500 women may not represent a random sample of all participants and we cannot be certain that our estimates of test-retest reliability are unbiased. The possibility that members of MZ twin pairs are more likely to attend the same doctors (who might influence their patients' behaviours in similar ways) than DZ co-twins was not measured directly. In our separate analyses of use of hysterectomy and gynaecologists, this was not found to be a significant factor (data not shown). 
Our study was conducted before the introduction of national policies and organised programmes with clear and consistent guidelines for screening onset and rescreening intervals. This was an advantage in that twins' behaviours were less likely to have been influenced by the same media messages. Nevertheless, the messages are by no means yet universally recognised. Following the introduction of the national breast screening programme, some women were still uncertain about why screening is important and about recommended age for commencement of mammography and intervals for rescreening. ${ }^{57} \mathrm{On}$ the other hand, if there is indeed a more uniform information environment and consistent practitioner guidelines, further study of these female twin pairs may be even more informative in identifying individual factors predisposing women to preventive health behaviours now that Australia is some years down the track following the introduction of national screening programmes.

\section{Acknowledgements}

The study was supported by grants from the National Health and Medical Research Council (Australia, 941177, 971232), and National Institute of Alcoholism and Alcohol Abuse (USA, AA07535, AA07728, AA10249). ST was the recipient of an Australian National Health and Medical Research Council (NHMRC) Biomedical Postgraduate Scholarship. We are grateful to Olivia Zheng, Sue Mason and Ann Eldridge for assistance with data collection at the 1989 survey, and we especially thank the twins for their cooperation.

\section{References}

1 Australian Institute of Health and Welfare. Australia's Health 1994. Australian Government Publishing Service: Canberra, 1994.

2 McCredie M, Hopper JL, Cawson JN. Risk factors and preventive strategies for breast cancer. Med J Aust 1995; 163(8): 435-440.

3 Smith CL, Kricker A, Armstrong BK. Breast cancer mortality trends in Australia: 1921 to 1994. Med J Aust 1998; 168(1): 11-14.

4 Butler J, Furnival C, Hart R. The costs of treating breast cancer in Australia and the implications for breast cancer screening. Aust N Z J Surg 1995; 65(7): 485-491.

5 Daunter B, Shield P. The Pap smear is alive and well. Modern Med Aust 1989; 32(3): 14-23.

6 Mitchell H. Pap smear screening in Australia. Modern Med Aust 1989; 32(3): 27-31.

7 Office of the Status of Women. Australian Women's Year Book 1994. Australian Bureau of Statistics: Canberra, 1994.

8 Palmer GR, Short SD. Health Care and Public Policy: An Australian Analysis, 2nd edn. Macmillan: Melbourne, 1996.
9 Faulkner K. An Analysis of the Literature on the Implementation of the National Policy for Screening to Prevent Cancer of the Cervix, Using an Acceptability Framework. Master of Health Science: Queensland University of Technology, 1997.

10 Young M, Trevan E. Pap smear usage in New South Wales impact of active promotion. Comm Health Stud 1990; 14: 255-262.

11 Dickinson J, Leeder S, Sanson-Fisher R. Frequency of cervical smear-tests among patients of general practitioners. Med J Aust 1988; 148: 128-131.

12 Beral V, Hermon C, Munoz N, Devesa SS. Cervical cancer. Cancer Surv 1994; 20: 265-285.

13 Mitchell H, Medley G. Age and time trends in the prevalence of cervical intraepithelial neoplasia on Papanicolaou smear tests, 1970-1988. Med J Aust 1990; 152(5): 252-255.

14 Mitchell H. Organized mammographic screening programmes - A benign or malignant neglect? Med J Aust 1987; 146: 87-90.

15 Redman B. The Process of Patient Teaching in Nursing. The CV Mosby Company: St Louis, 1976.

16 True WR, Romeis JC, Heath AC, Flick LH, Shaw L, Eisen SA, Goldberg J, Lyons MJ. Genetic and environmental contributions to healthcare need and utilization: A twin analysis. Health Service Res 1997; 32(1): 37-53.

17 Martin N, Eaves L, Kearsey M, Davies P. The power of the classical twin study. Heredity 1978; 40: 97-116.

18 Martin N, Boomsma D, Machin G. A twin-pronged attack on complex traits. Nat Genet 1997; 17: 387-392.

19 Jardine R, Martin N, Henderson A. Genetic covariation between neuroticism and the symptoms of anxiety and depression. Genet Epidemiol 1984; 1: 89-107.

20 Martin N, Jardine R. Eysenck's contributions to behaviour genetics. In: Modgil S, Modgil C, eds. Hans Eysenck: Consensus and Controversy. Falmer Press: Philadelphia, 1986: 13-47.

21 Eaves L, Fulker D, Heath A. The effects of social homogamy and cultural inheritance on the covariances of twins and their parents: a LISREL model. Behav Genet 1989; 19: 113-122.

22 Heath A, Cloninger C, Martin N. Testing a model for the genetic structure of personality: A comparison of the personality systems of Cloninger and Eysenck. J Pers Soc Psychol 1994; 66: 762-775.

23 Treloar S, Martin N, Dennerstein L, Raphael B, Heath A. Pathways to hysterectomy: insights from longitudinal twin research. Am J Obstet Gynecol 1992; 167(1): 82-88.

24 Treloar S, Martin N, Heath A. Longitudinal genetic analysis of menstrual flow, pain and limitation in a sample of Australian twins. Behav Genet 1998; 28(2): 107-116.

25 Martin N, Martin P. The inheritance of scholastic abilities in a sample of twins. I. Ascertainment of the sample and diagnosis of zygosity. Ann Hum Genet 1975; 39: 213-218.

26 Eaves L. The zygosity of twins: further evidence on the agreement between the diagnosis by blood group and written questionnaires. J Biosoc Sci 1976; 8: 263-266.

27 Ooki S, Yamada K, Asaka A, Hayakawa K. Zygosity diagnosis of twins by questionnaire. Acta Genet Med Gemellol (Roma) 1990; 39: 109-115.

28 Duffy D. Asthma and Allergic Diseases in Australian Twins and Their Families. Doctor of Philosophy thesis: University of Queensland, 1994.

29 Cloninger C, Przybeck T, Svrakic D. The Tridimensional Personality Questionnaire: U.S. normative data. Psychol Rep 1991; 69: 1047-1057.

30 Eysenck H, Eysenck S, Barrett P. A revised version of the psychoticism scale. Pers Indiv Differences 1985; 6: 21-29.

31 Cloninger C. A systematic method for clinical description and classification of personality variants: A proposal. Arch Gen Psychiatry 1987; 44: 573-588.

32 Eysenck H, Eysenck M. Personality and Individual Differences. Plenum Press: New York, 1985. 
33 Bedford A, Foulds G, Sheffield B. A new personal disturbance scale (DSSI sAD). Br I Soc Clin Psychol 1976; 15: 387-394.

34 Bedford A, Foulds G. Validation of the Delusions-SymptomsStates Inventory. Br J Med Psychol 1977; 50: 163-171.

35 Derogatis LR, Rickels K, Rock A. The SCL-90 and the MMPI a step in the validation of a new self-report scale. Br J Psychiatry 1976; 128: 280-289.

36 Derogatis L, Lipman RS, Rickels K, Uhlenhuth E, Covi L. The Hopkins Symptom Checklist (HSCL). In: Pichot P (ed.). Psychological Measurements in Psychopharmacology. Modern Problems in Pharmacopsychiatry. Karger: Basel, 1974: pp 79-110.

37 Rosenberg M. Society and the Adolescent Self-image. Princeton University Press: Princeton, NJ, 1965.

38 Pearlin L, Schooler C. The structure of coping. J Health Soc Behav 1978; 19(1): 2-21.

39 Hirschfeld R, Klerman G, Gough H, Barrett J, Korchin S, Chodoff P. A measure of interpersonal dependency. J Pers Assess 1977; 4: 610-618.

40 Hirschfeld R, Klerman G, Chodoff P, Korchin S, Barrett J. Dependency - self-esteem - clinical depression. J Am Acad Psychoanalysis 1976; 4: 373-388.

41 Folkman S, Lazarus R. An analysis of coping in a middle-aged community sample. J Health Soc Behav 1980; 21: 219-239.

42 Folkman S, Lazarus R. If it changes it must be a process: study of emotion and coping during three stages of a college examination. 1985; 48: 150-170.

43 Kendler K, Kessler R, Heath A, Neale M, Eaves L. Coping - a genetic epidemiological investigation. Psychol Med 1991; 21: 337-346.

44 Jöreskog K, Sörbom D. DOS Extender PRELIS 2.12a. Scientific Software International Inc: Chicago, 1993.

45 Jöreskog K, Sörbom D. LISREL 8.1. Chicago: SPSS Inc, 1993.

46 Mather K, Jinks J. Introduction to Biometrical Genetics. Cornell University Press: Ithaca, New York, 1977.
47 Eaves L. Aspects of Human Psychogenetics. Doctor of Philosophy: University of Birmingham, 1970.

48 Neale M, Cardon L. Methodology for Genetic Studies of Twins and Families. NATO ASI Series. Kluwer Academic Publishers: Dordrecht, The Netherlands, 1992.

49 Heath A, Neale M, Hewitt J, Eaves L, Fulker D. Testing structural equation models for twin data using LISREL. Behav Genet 1989; 19(1): 9-35.

50 Kendler K, Silberg J, Neale M, Kessler R, Heath A, Eaves L. Genetic and environmental factors in the aetiology of menstrual, premenstrual and neurotic symptoms - a populationbased twin study. Psychol Med 1992; 22: 85-100.

51 Bucholz KK, Madden PAF, Dinwiddie SH, Slutske WS, Beirut LJ, Statham DJ, Dunne MP, Whitfield JB, Martin NG. Genetic and environmental contributions to alcohol dependence risk in a national twin sample: consistency of findings in women and men. Psychol Med 1997; 27: 1381-1396.

52 SAS Institute Inc. SAS/STAT user's guide. Version 6. SAS Institute Inc: Cary NC, 1997.

53 Straton J, Holman C, Edwards B. Cervical cancer screening in Western Australia in 1992: progress since 1983. Med J Aust 1993; 159: 657-661.

54 Steven ID, Dickens E, Thomas SA, Browning C, Eckerman E. Preventive care and continuity of attendance. Is there a risk? Aust Fam Physician 1998; 27 Suppl 1: S44-S46.

55 Wai D, Ferrier A, Collings S, Laverty C. Have the most recent Pap smear guidelines affected GP practices? Aust Fam Physician 1996; 25 Suppl 1: S44-S48.

56 Baker LA, Treloar SA, Reynolds CA, Heath AA, Martin NG. Genetics of educational attainment in Australian twins: Sex differences and secular changes. Behav Genet 1996; 26(2): 89-102.

57 Barratt AL, Cockburn J, Redman S, Paul C, Perkins J. Mammographic screening: results from the 1996 National Breast Health Survey. Med J Aust 1997; 167(10): 521-524. 